\title{
Investigation of the influence of effect-yarn draw and effect-yarn overfeed on texturing performance: comparison between air-jet and steam-jet textured yarn
}

\author{
Ganemulle Lekamalage Dharmasri Wickramasinghe ${ }^{1^{*}}$ and Peter William Foster ${ }^{2}$
}

\footnotetext{
* Correspondence: dharmasri@uom.lk 1 Department of Textile and Clothing Technology, University of Moratuwa, Moratuwa 10400, Sri Lanka

Full list of author information is available at the end of the article
}

\begin{abstract}
The objective of this research work was to investigate the use of steam as a substitute fluid for air in spun-like textured yarn manufacturing. The new substitute product holds the potential for competitive advantage, lower manufacturing costs and streamlined manufacturing capabilities. Generally high-pressure steam is known to be cheaper to produce than compressed air. An existing air-jet texturing machine was modified to supply either air or steam to the texturing nozzle. Using an identical nozzle, both air-jet and steam-jet textured yarns were manufactured. The influence of effect-yarn parameters on the steam-jet texturing performance has been studied. Furthermore, steam-jet texturing was compared with air-jet texturing in terms of the processing parameters and the textured yarn properties. The results show that spun-like textured yarn manufactured using steam has lower loop instability, lower loop density and higher tensile properties than air at comparable fluid pressures. SEM image analysis shows that the entangled structure of the steam-jet textured yarns is comparable to the air-jet textured yarns. To verify the commercial feasibility of the new product, sewing threads were manufactured using both steam-jet and air-jet textured yarns and tested for sewability under commercial specifications. Sewability results indicated that the steam-jet textured sewing threads can withstand sewing at high-speeds like air-jet textured threads and are therefore suitable for manufacture of sewing threads. Therefore, it can be concluded that steam can be used as an alternative fluid for air in making spun-like textured yarns.
\end{abstract}

Keywords: Air-jet texturing; Steam-jet texturing; Spun-like textured yarn; Effect-yarn overfeed; Effect-yarn draw; Sewing threads

\section{Introduction}

One of the significant texturing processes in current use, air-jet texturing, operates by mechanical interlocking and not by heat setting in the case of the other texturing techniques such as false-twist. It is a cold fluid texturing process that converts flat, continuous synthetic filament yarns into an entangled, convoluted, bulky, spun-like yarn. Air-jet texturing has three types based on the supply yarn. Single-end air-jet texturing denotes the situation whereby single filament yarn is overfed to the texturing nozzle, and the resultant textured yarn is withdrawn. In case of parallel air-jet

\section{Springer}

(c) 2014 Wickramasinghe and Foster; licensee Springer. This is an open access article distributed under the terms of the Creative Commons Attribution License (http://creativecommons.org/licenses/by/2.0), which permits unrestricted use, distribution, and reproduction in any medium, provided the original work is properly cited. 
texturing, two or more filaments yarns are fed at the same overfeed into the nozzle so as to facilitate a blend of different types of supply material, or of the same material but with different filament linear densities or number of filaments, or different cross sectional shapes. In core-effect air-jet texturing two different filament yarns are fed under different overfeeds into the air-jet at the same time. In core-effect air-jet texturing, the lower overfeed yarn is called the core-yarn and the higher overfeed yarn is called the effect-yarn. The core-yarn overfeed determines the strength of the textured yarn. The effect-yarn overfeed determines the size of the protruded loops. It also has an indirect influence upon the number of loops per unit length and also on the linear density. Perhaps the most important influence of the effect-yarn overfeed is to be seen in the structure and appearance of the yarn. This is because loops are seen on the surface of the yarn in the same way that hairs are visible in a spun yarn. However, there is limited literature on core-effect air-jet texturing or the influence of the effect-yarn parameters on air-jet texturing performance. Researchers have not given adequate prominence in core-effect air-jet texturing and most of the research limited to singleend air-je texturing. Wickramasinghe (2003) has investigated the use of steam as an alternative fluid for air in spun-like textured yarn manufacturing and studied the performance of sewing threads manufactured using core-effect steam-jet textured yarns. He reported that steam could be used as an alternative fluid for air in manufacturing core-effect spun-like textured sewing threads.

In the beginning, air-jet textured yarns were produced by blowing a stream of air into twisted continuous filament yarns, while they were being overfed to the take-up bobbin (Wray \& Entwistle 1968). Studies in the 1960s by Wray and Entwistle (1969) were followed those by Sivakumar (1975) in the early 1970s. Since 1980s, researchers have mainly focused on investigating the effect of process parameters, nozzle geometry, and the air-flow behaviour on yarn texturing. Researchers (Acar 1988; Acar et al. 1986b; Rangasamy et al. 1990) have studied the effect of filament fineness and concluded that the filaments with finer linear densities are more suitable for air-jet texturing due to their less bending and torsional stiffness that blow the filaments more easily that enhance the entanglement effectiveness. Supply yarn properties are important for texturing since resultant forces acting on filaments are determined by the fluid forces acting on the filaments (Acar 1991; Acar et al. 1986b). Further Acar et al. (1986c) found that the filament cross section also has direct influence on texturing and concluded that the non-circular filament cross sections have better filament texturing due to larger surface areas than the circular filament of equal linear density. Spin finish on filaments has a negative effect on the texturing process due to contamination of the texturing nozzle (Simmen 1987). However, researchers (Acar 1988; Acar \& Demir 1987) dispute the above explanation and argued that most of the spin finish blow off from the filament due to the secondary air-low and the new jets are self cleaned. They suggest using a suitable spin-finish for air-jet texturing which removes them in filament wetting that improves the filament flexibility. Feeder yarn wetting was studied by many researchers (Acar \& Demir 1987; Acar et al. 1986d; Acar et al. 1986a; Demir et al. 1988; Fisher \& Wilson 1982; Kothari \& Timble 1991) and reported that the feeder yarn wetting before the air-jet nozzle influence the stability of the texturing process as well as the textured yarn properties. Recent studies by Acar et al. (2006) reported that water acted as lubricant to reduce friction between the filaments in the air-jet texturing process. Study 
by Kothari et al. (1996) attempted to characterise the structure of air-jet textured yarns in terms of migration parameters. Since air-jet texturing process was developed to feed POY yarns, research were carried out by Sengupta et al. (1989) to understand the influence of drawing variables on the properties of air-jet textured yarns made from POY feeder yarns.

Theoretical investigation on nozzle parameters and air -flow on air-jet texturing was carried out by Acar et al. (1986a, 1986e); Bilgin et al. (1996); Demir et al. (1987), and Versteeg et al. (1994), but the actual behaviour of the filament during texturing in supersonic flow was not properly understood. Acar et al. (1986b) have attempted to understand the actual filament behaviour during texturing using high speed photography techniques. Acar \& Wray (1986) and Kothari \& Timble (1991) investigated the effect of processing parameters such as jet type, overfeed ratio, air-pressure, production speed, yarn wetting and baffle-ball on yarn properties in terms of tensile properties, liner density and instability. Effect of baffle geometry and baffle setting was studied by Kothari et al. (1995) and found baffle parameters are critical to texturing and textured yarn properties.

Researchers have attempted to investigate the application of air-textured yarn in industrial and technical applications. Koc et al. (2008) analysed the effect of airtexturing on adhesion behaviour to rubber and concluded that air-jet texturing increase the surface area of the yarn structure and higher adhesion of polyester fabric to rubber could be achieved by air-jet texturing. Research by Mahmood et al. (2013a, 2013b) used core-effect textured glass yarns for improving the bonding strength of laminated glass woven fabric composites and conclude that the air-jet texturing introduces bulk and loops in the yarn which provides more contact surface between the fibres and the resin.

\section{Objectives}

Since air-jet textured yarn has already been established within the industry, it is vital to improve the yarn quality while reducing the production cost. Since the production costs have already been reduced significantly by minimising compressed air consumption and using POY etc., attention is now needed at saving costs elsewhere. One option would be to find a cheaper substitute fluid for air as a texturing medium. There is no literature regarding this so far. The aim of this paper is to develop the use of high-pressure steam, as a substitute fluid for compressed air to produce spun-like textured yarn. The new product holds the potential for competitive advantage, lower manufacturing costs and streamlined manufacturing capabilities. The idea is to take the technology of air-jet texturing and to modify the process so that high-pressure steam can be used as the texturing medium. Furthermore, study of the effect of effect-yarn draw ratio and overfeed percentage is critical for the textile application perspectives since surface characteristic of the core-effect spun like textured yarn is mainly determined by the effect-yarn overfeed.

Generally high-pressure steam is known to be cheaper to produce than compressed air. This factor is critical when it is considered that the largest obstacle to the development of a successful performance air-jet textured yarn has been the energy cost involved in generating compressed air. Although the reduced cost of a pressurised fluid was of great interest on its own, high pressure steam has extra useful properties such as the in-built high energy content which could theoretically be used to thermally set the thread, thus obviating the need for separate electric heaters to achieve stabilisation. This could reduce further the energy requirement of the process and simplify the 
production machine design thus driving down cost further. The aim of this paper is to analyze and compare the properties of steam-jet textured yarns with air-jet textured yarns made under similar process conditions with varying effect-yarn draw ratio and overfeed. Furthermore, sewing threads were manufactured using both air-jet and steam-jet textured yarns and tested for sewability of the threads to check the feasibility of this yarns for sewing thread applications.

\section{Methods}

\section{Texturing equipment}

A single position commercial air-jet texturing machine was modified to make both airjet and steam-jet textured yarns under similar processing parameters. The machine has two feed rollers where the effect yarn overfeed can be changed from $37.9 \%$ to $53.0 \%$. The machine was designed originally to supply compressed air to the texturing nozzle. At the start of the steam-jet texturing research, the machine was modified to supply either compressed air or high-pressure steam for the texturing nozzle. The jet box seal was modified to prevent steam and condensate from escaping. This also reduced the noise level and improved the safety of the steam process. Following process parameters, which are based on commercial specification in making 120 ticket number (TKT) air-jet sewing thread, have been maintained constant in the study so as to eliminate the effects of other parameters on texturing.

Processing parameters

Fluid pressure: 8 bar (air and steam)

Production speed: $275 \mathrm{~m} / \mathrm{min}$

Core yarn: Polyester 415dtex/ f48 POY

Core yarn draw ratio: 2.19 at $110^{\circ} \mathrm{C}$ draw pin temperature

Core yarn pre-heating temperature: $180^{\circ} \mathrm{C} / 10$ wraps at Godet roller

Core yarn overfeed: $5.5 \%$

Effect yarn: Polyester 86dtex/ f36 POY

Effect yarn draw ratio: 1.65 to 1.82 at $70^{\circ} \mathrm{C}$ draw pin temperature

Effect yarn overfeed: $37.9 \%$ to $53.0 \%$

Baffle ball setting: $1.5 \mathrm{~mm}$

Core yarn wetting: $\mathrm{ON}$

\section{Measurement of yarn tension}

Core-yarn and textured yarn tension measurements have been made using a Rothschild INTEG series 82 tension head. The data have been analysed using associated computer software. Average yarn tension values have been used in analysing the results from the texturing process.

\section{Measurement of the loop instability}

The loop instability test method which is based on load elongation curves of the textured yarn was used in this study. The loads used are $0.01 \mathrm{cN} / \mathrm{dtex}$ (lower limit) and $0.5 \mathrm{cN} / \mathrm{dtex}$ (upper limit). The difference in elongations, which corresponds to the loads, provides a measurement of the instability of the textured yarn. 


\section{Measurement of loop density}

Loop density is defined as the number of loops available on the surface of the textured yarn per unit length. Although the loop instability gives an indication of the level of texturing, it does not indicate the number of surface loops. A reliable method to identify the amount of surface loop is important. The author has attempted to visually count the number of loops per unit length on the yarn surface by using a video microscope. Such an evaluation was subjective, tedious and laborious. Therefore, as an alternative method, the SDL friction and hairiness tester was used to measure number of loops available on the surface. According to the SDL tester specifications for staple spun yarns, it is recommended that a $3 \mathrm{~mm}$ setting be used to measure fibre ends. The $3 \mathrm{~mm}$ setting measures number of fibres that are higher than $3 \mathrm{~mm}$. However, the author has found that most of the loops that are available on the air-jet and steam-jet textured yarns are smaller than $3 \mathrm{~mm}$; therefore a $3 \mathrm{~mm}$ setting does not indicate the actual amount of loops on the surface. If we could, it would be ideal to measure all the loops above the surface of the yarn. That means the setting has to be closer to $0 \mathrm{~mm}$. However, by trial and error, the author has found that the minimum reliable setting that could be used in the hairiness tester is $1 \mathrm{~mm}$ and this value has subsequently been used. A length of $10 \mathrm{~m}$ with the yarn moving at a speed of $30 \mathrm{~m} / \mathrm{min}$ was chosen. Ten samples have been tested and the average number of loops per $10 \mathrm{~cm}$ calculated. For convenience, the researcher has defined the results obtained by the hairiness tester as 'loop density'.

\section{Measurement of tensile properties}

Tensile properties of the core-yarns and textured yarns were measured with an UsterTensorapid automatic yarn-testing instrument. The instrument is a single yarn strength tester and operates at a constant rate of extension. Following BS EN ISO 2062:1995, with a sample length of $50 \mathrm{~cm}$, the cross head moving speed has been adjusted to give a yarn failure time of $20 \pm 3$ seconds. Twenty tests have been carried out for each package and the average strength, tenacity and elongation results have been obtained from five packages where possible.

\section{Measurement of linear density}

To measure linear density, $100 \mathrm{~m}$ length of yarns have been wound on a wrap reel with a $1 \mathrm{~m}$ circumference and were weighed on an electronic analytical balance, which had a sensitivity of $0.1 \mathrm{mg}$. Linear density in tex was calculated. Average linear density was taken from five samples.

\section{Results and discussion}

\section{Effect-yarn draw ratio}

Draw ratio affects the physical properties of effect-yarn, such as count, tenacity, elongation and flexibility etc. Generally, the effect-yarn draw ratio is maintained at a lower level than the core-yarn, so that one can later reduce the loop size by heat setting of the textured yarn. Polyester 86dtex/f36 POY yarns have been used as the effect-yarn in the study. The effect-yarn draw ratios have been changed between 1.65 and 1.82 using the appropriate change wheels.

\section{Core-yarn tension $\left(T_{1}\right)$ and textured yarn tension $\left(T_{2}\right)$}

Figure 1 shows that at constant effect yarn overfeed for air-jet and steam-jet texturing, $\mathrm{T}_{1}$ and $\mathrm{T}_{2}$ values are not sensitive to the effect-yarn draw ratio. It can be concluded 


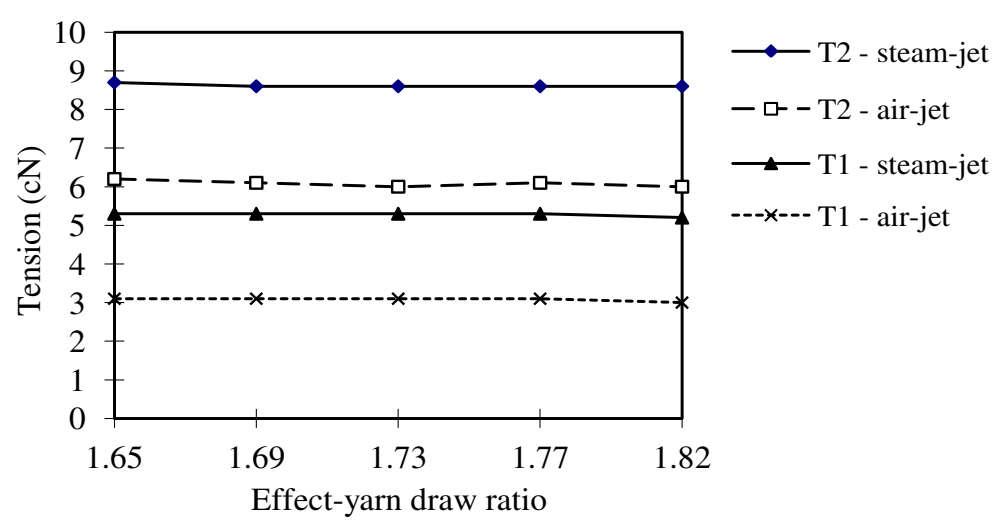

Figure 1 Effect of effect-yarn draw ratio on core yarn tension $\left(T_{1}\right)$ and textured yarn tension $\left(T_{2}\right)$.

that effect-yarn draw ratio does not affect stability of the texturing process. $T_{1}$ and $T_{2}$ values for the steam-jet texturing are higher than for the air-jet texturing for the effectyarn draw ratios studied, apparently due to the effect of shrinkage.

\section{Loop instability of textured yarns}

Figure 2 shows that loop instability for both yarns decreases marginally when effect-yarn draw ratio is increased. This indicates that core and effect filaments are effectively entangled when the effect-yarn has a higher draw, although the trend is only small. At higher draw ratios, the yarn is finer and has lower flexural rigidity. Therefore, effect-yarn filaments may entangle more efficiently with the core-yarn filaments and lead to the lower loop instability. The loop instability of steam-jet is lower than the loop instability of air-jet textured yarns, which conforms with earlier results.

\section{Loop density of textured yarns}

Figure 3 shows that loop density of steam-jet textured yarns increases and air-jet textured yarn decreases when effect-yarn draw ratio is increased. The decrease of loop density in the case of air-jet textured yarns may be due to smaller loops. It suggests that the increase of effect-yarn draw ratio increases the level of texturing and hence make smaller loops.

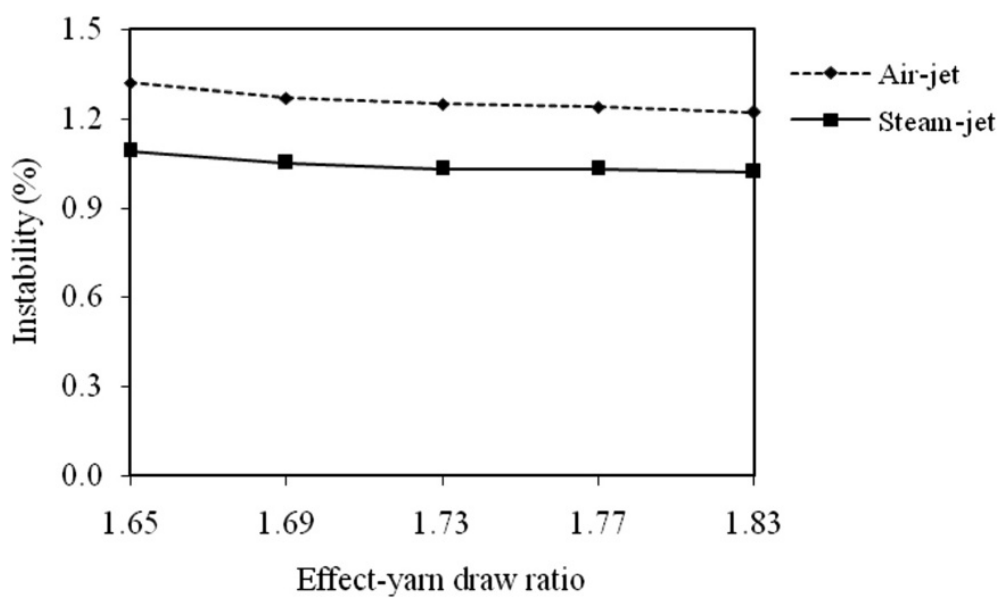

Figure 2 Effect of effect-yarn draw ratio on loop instability of textured yarns. 


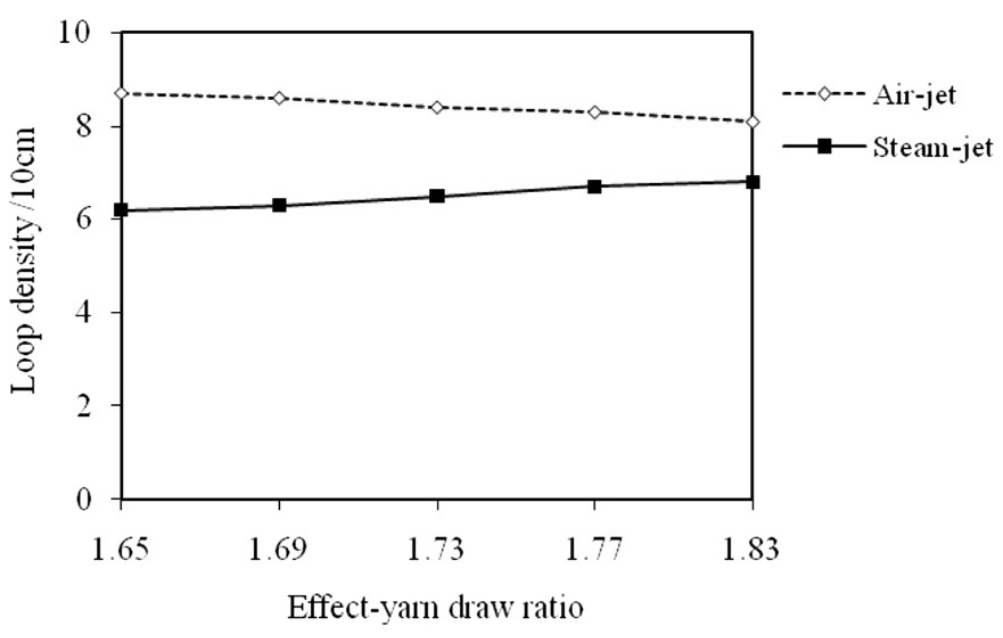

Figure 3 Effect of effect-yarn draw ratio on loop density of textured yarns.

The increase of loop density in the case of steam-jet textured yarns, could due to higher level of entanglement. The results conform to earlier results suggesting that more entangled yarns have more loops due to the smaller effect of shrinkage. The results are consistent with the earlier results that steam-jet textured yarns have lower loop density than air-jet textured yarns. It is believed that the steam shrinks the loops of yarn in texturing.

\section{Physical properties of textured yarns}

Figures 4, 5, 6 and 7 shows that strength, tenacity, elongation and linear density for both yarns decrease when effect-yarn draw ratio is increased. Effect-yarn tenacity increases when draw ratio is increased. Therefore, the tenacity of the textured yarn should increase when the effect yarn draw ratio is increased, if the level of texturing remains constant. On the other hand when the effect draw ratio is increased, the effect-yarn linear density decreases and hence the final linear density of the yarn decreases. The tenacity of the textured yarn increases when the linear density decreases. Therefore, decrease of tenacity and strength of the textured yarns shows that the level of texturing is increasing as the effect-yarn draw ratio is increased for both air-jet and steam-jet textured yarns.

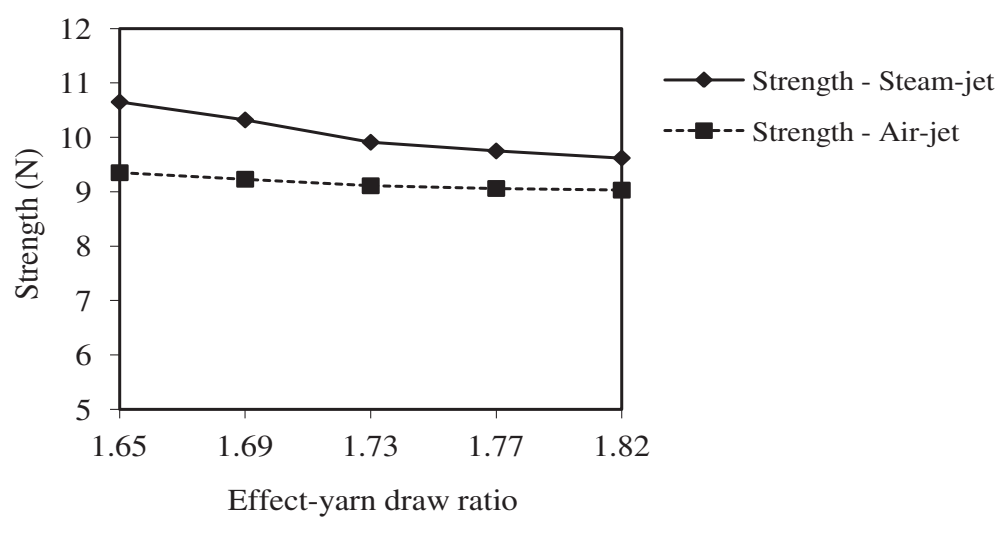

Figure 4 Effect of effect-yarn draw ratio on strength of textured yarns. 


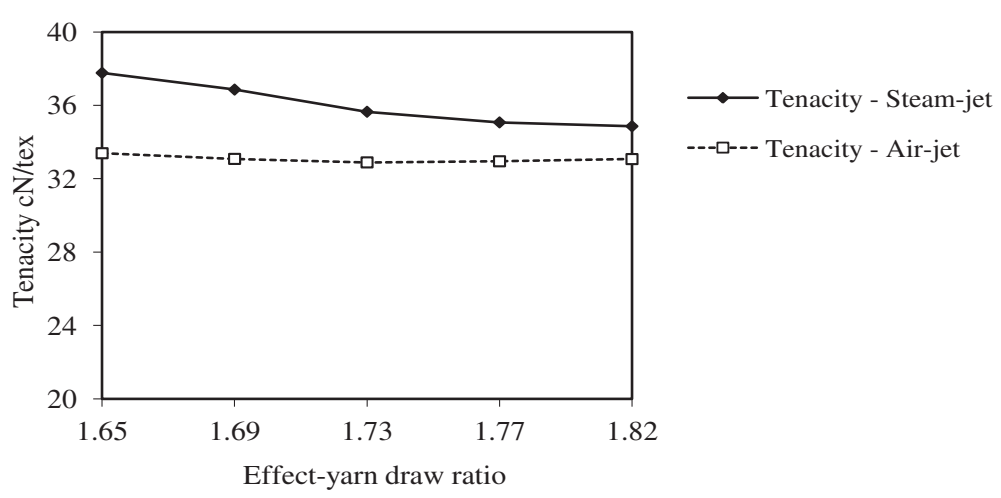

Figure 5 Effect of effect-yarn draw ratio on tenacity of textured yarns.

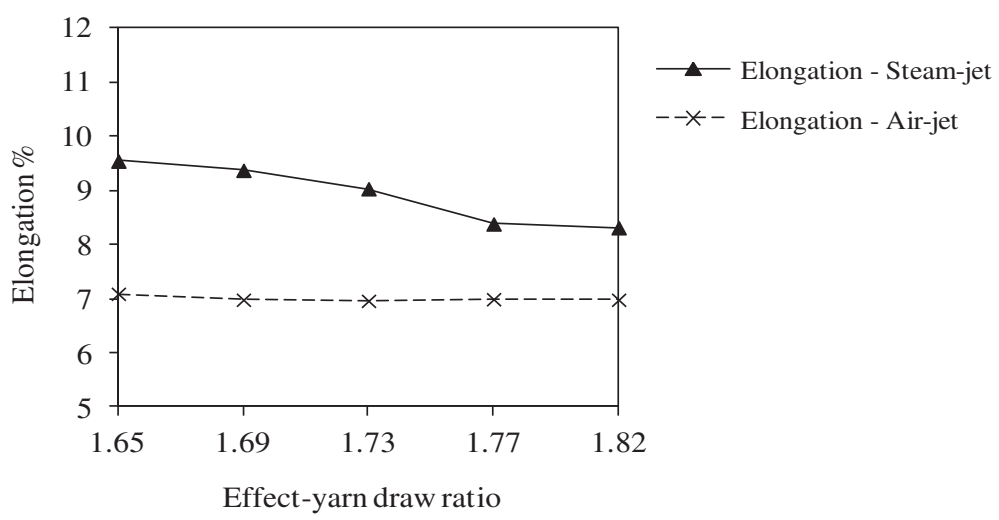

Figure 6 Effect of effect-yarn draw ratio on elongation of textured yarns.

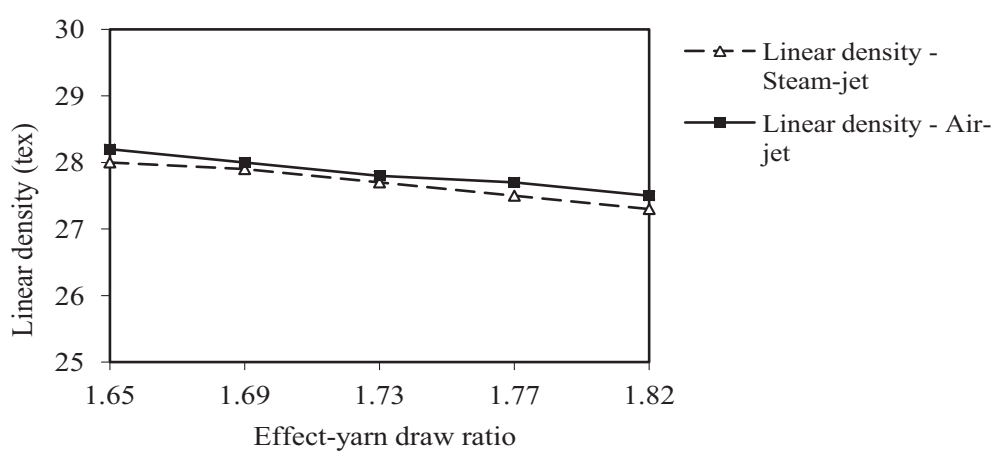

Figure 7 Effect of effect-yarn draw ratio on linear density of textured yarns.

\section{Microscopic observations}

Microscopic inspections show that there was no detectable visual difference in the structure of the textured yarns as the effect-yarn draw ratio was changed.

\section{Effects of effect-yarn overfeed}

In this study, polyester $86 \mathrm{dtex} / \mathrm{f} 36$ POY yarn has been used as the effect-yarn. The effectyarn overfeed has been controlled mechanically by varying the speed of effect-yarn 


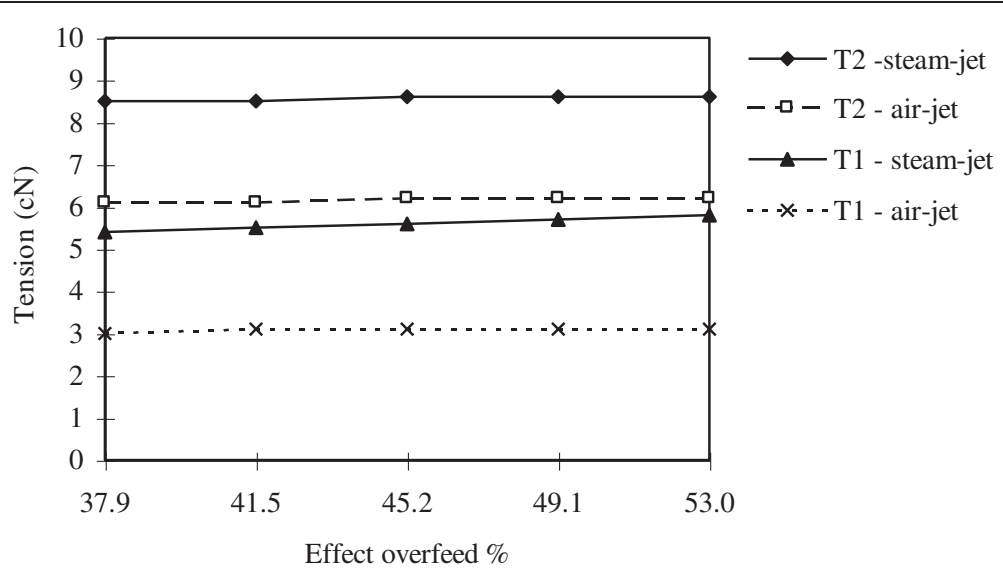

Figure 8 Effect of effect-yarn overfeed on core yarn tension $\left(T_{1}\right)$ and textured yarn tension $\left(T_{2}\right)$.

feed roller relative to the given production speed. Using change wheels, the effectyarn overfeed percentage has been changed between 37.9 percent and 53.0 percent.

\section{Core-yarn tension $\left(T_{1}\right)$ and textured-yarn tension $\left(T_{2}\right)$}

Figure 8 shows the variation of $\mathrm{T}_{1}$ and $\mathrm{T}_{2}$ against effect-yarn overfeed. In both air-jet and steam-jet texturing, $\mathrm{T}_{1}$ and $\mathrm{T}_{2}$ increase slightly when the effect-yarn overfeed is increased. Due to low core-yarn overfeed (5.5 percent) relative to the higher effectyarn overfeed, $\mathrm{T}_{1}$ and $\mathrm{T}_{2}$ is mainly controlled by the core yarn tension. Therefore, no substantial variation of $\mathrm{T}_{1}$ and $\mathrm{T}_{2}$ with effect-yarn overfeed would be expected. However, the results indicate that higher effect-yarn overfeed increases the level of core and effect filament entanglement and hence the overall texturing effect. When the air-jet and steam-jet texturing is concerned, it can be seen that $T_{1}$ and $T_{2}$ for steam-jet texturing are higher than for air-jet texturing at relevant overfeed.

\section{Loop instability of textured yarns}

Figure 9 illustrates that there is a slight decrease in loop instability with increasing effect-yarn overfeeds in both air-jet and steam-jet texturing. The decrease of loop

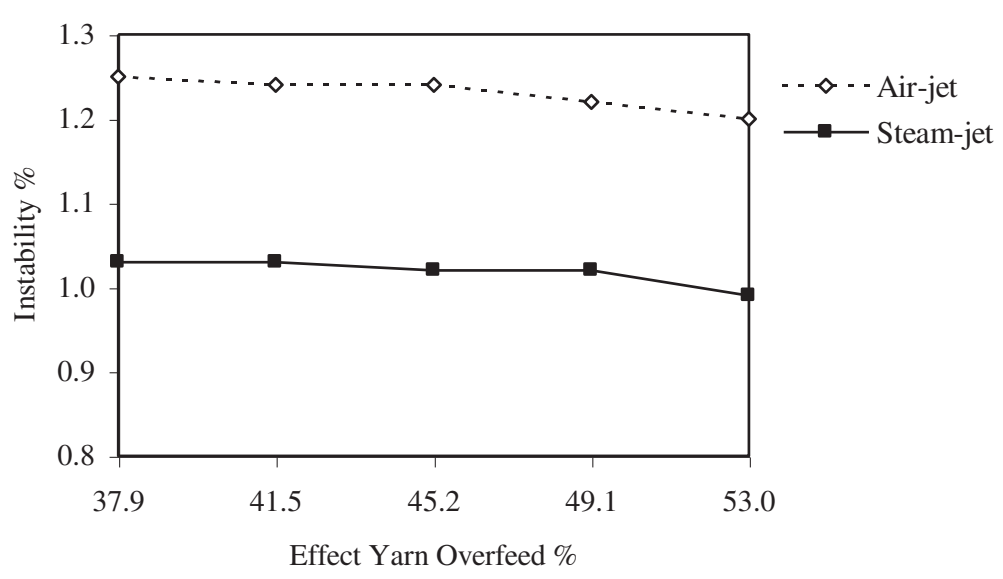

Figure 9 Effect of effect-yarn overfeed on loop instability of textured yarns. 


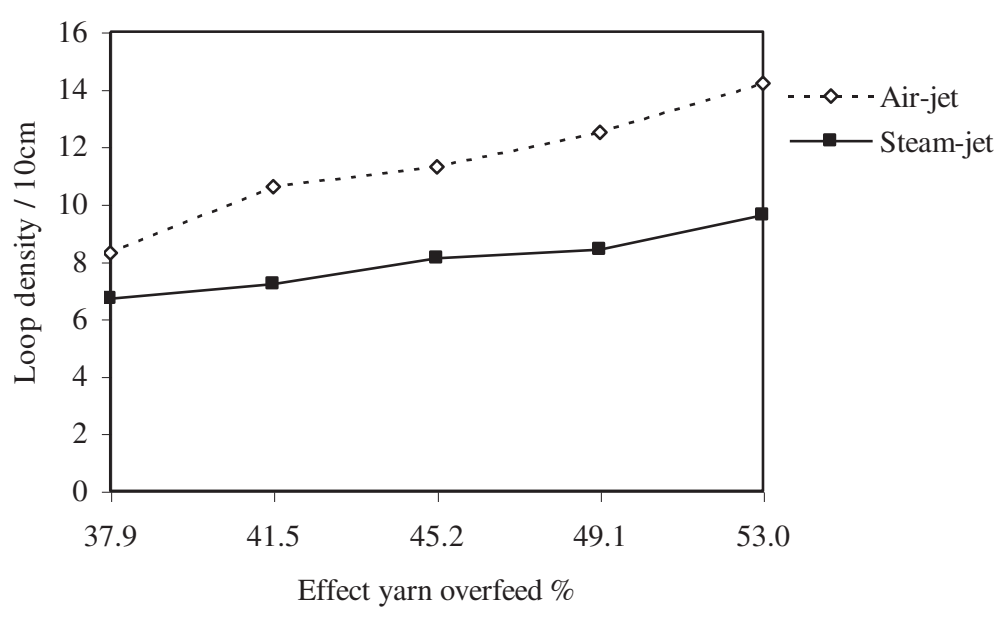

Figure 10 Effect of effect-yarn overfeed on loop density of textured yarns.

instability at higher effect overfeeds is probably due to more coherence in the core and effect filaments. Such coherence increases the friction and reduces the filament slippage. When the steam-jet and air-jet texturing is compared, steam-jet textured yarns give better results than air-jet textured yarns.

\section{Loop density of textured yarns}

Figure 10 shows that as expected, loop density increases in both steam-jet and air-jet textured yarns, when effect-yarn overfeed is increased. At higher effect-yarn overfeeds, there is an extra length of effect-yarn filaments available for loop formation. Such extra filaments will increase either the number of loops or the size of loops or both. Loop density of steam-jet textured yarns is lower than that of air-jet textured yarns. This may be due to the effect of shrinkage that reduces the loop size in steam-jet texturing.

\section{Boiling water shrinkage of textured yarns}

Figure 11 shows that there is no significant variation of boiling water shrinkage on changing the effect-yarn overfeed for both air-jet and steam-jet textured yarns. Boiling

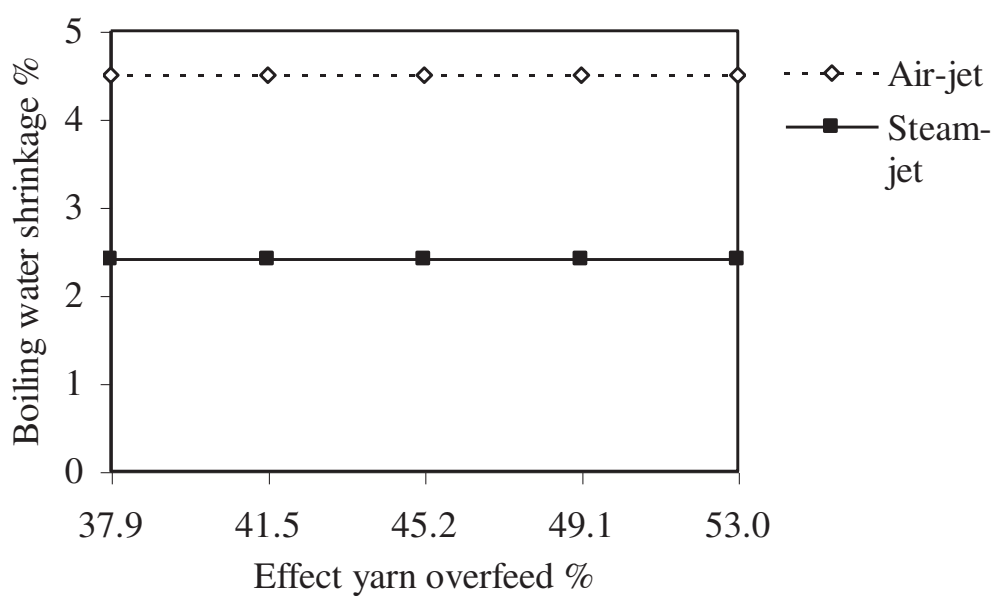

Figure 11 Effect of effect-yarn overfeed on boiling water shrinkage of textured yarns. 


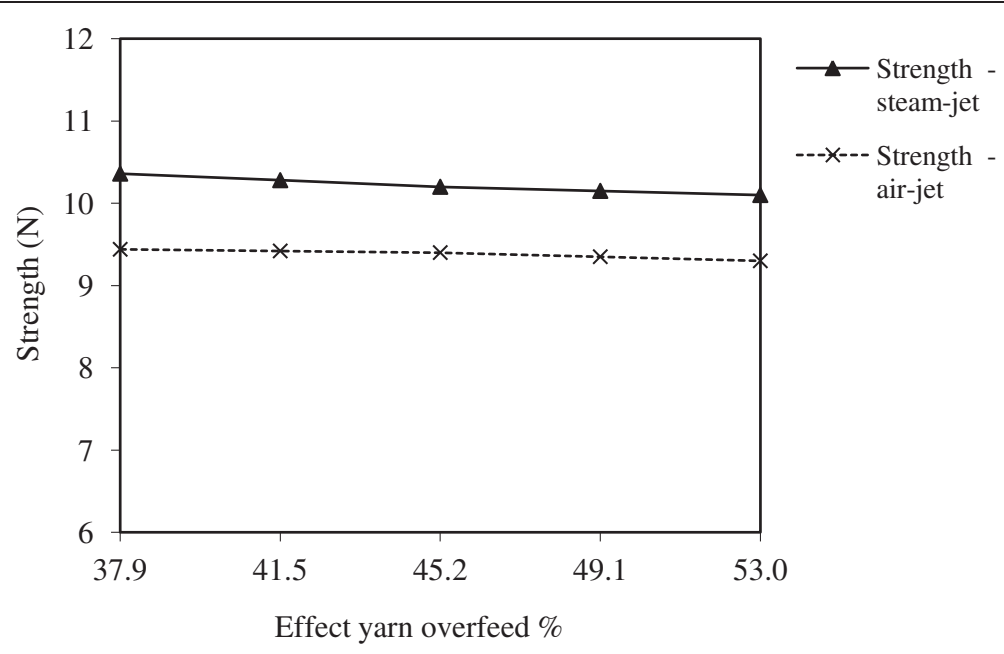

Figure 12 Effect of effect-yarn overfeed on strength of textured yarns.

water shrinkage of steam-jet textured yarn is lower than that of air-jet textured yarn as would be expected from earlier results. Therefore, shrinkage results complement with the previous assumption and results that the steam-jet textured yarn are shrinking during texturing.

\section{Physical properties of textured yarns}

Figures 12, 13, 14 and 15 show that strength, tenacity and elongation decrease and linear density increases with increasing effect-yarn overfeed in both air-jet and steamjet textured yarns. The results confirm the earlier suggestions made in previous sections that the increase of effect-yarn overfeed increases the level of core and effect xfilament entanglements. It is obvious that linear density increases with increasing effect-yarn overfeed as more lengths of effect filaments entangle with the core filaments. The tenacity, strength, elongation and linear density of steam-jet textured

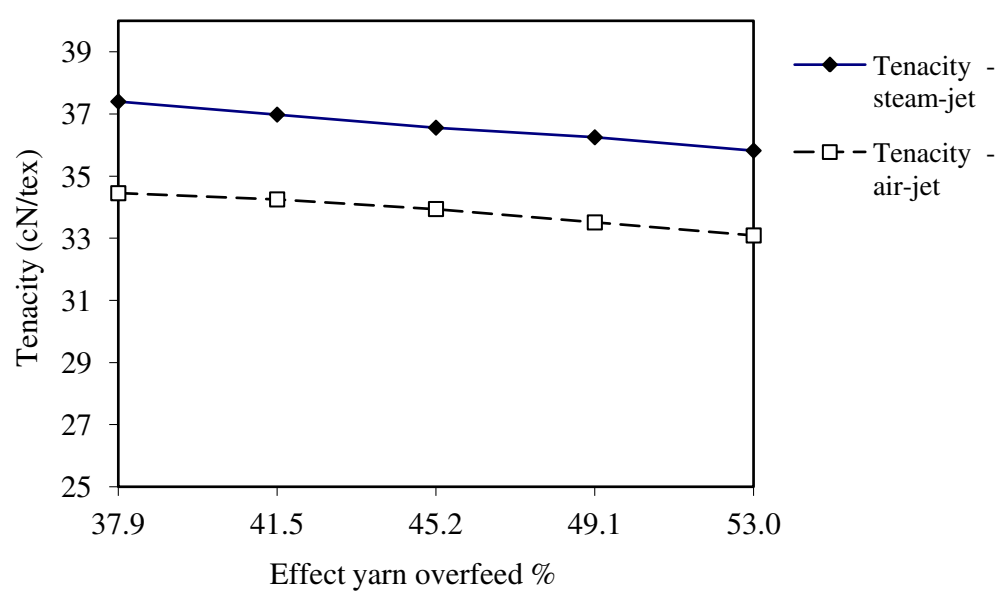

Figure 13 Effect of effect-yarn overfeed on tenacity of the textured yarn. 


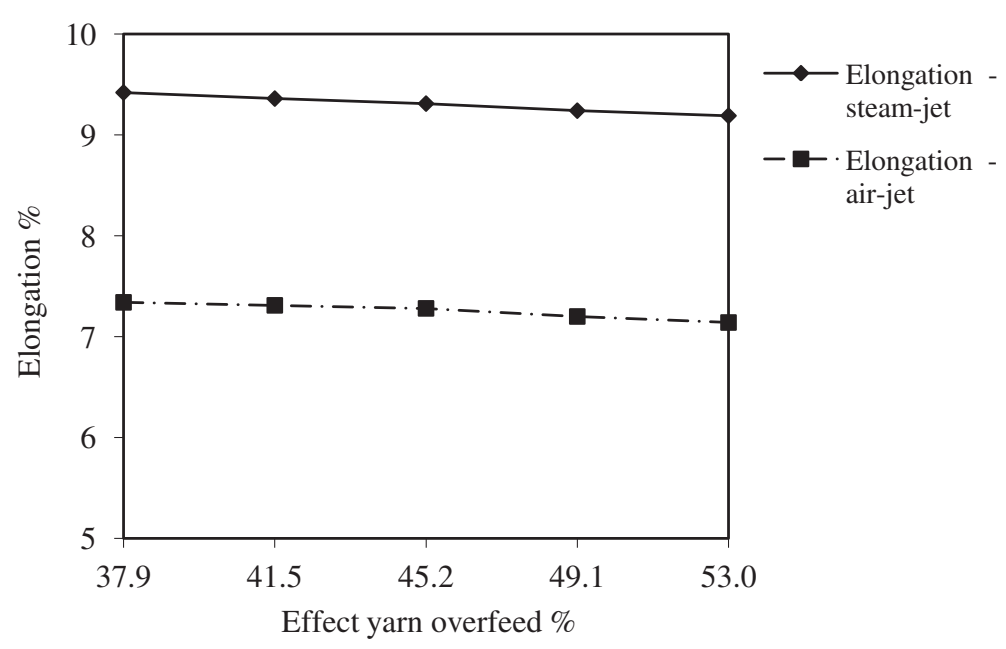

Figure 14 Effect of effect-yarn overfeed on elongation of textured yarns.

yarn are higher than air-jet textured yarn. However, compared with the other results, there is no evidence that the higher strength and tenacity of steam-jet textured yarn are mainly due to poor level of texturing. In fact, as far as sewing threads are concerned, if there is adequate texturing, higher strength and elongation would be an added advantage.

\section{Microscopic observations}

Microscopic inspection of the textured yarns has shown that both loop size and frequency increase when effect-yarn overfeed is increased. Figure 16 shows typical images of air-jet and steam-jet textured yarns manufactured using different effect-yarn overfeeds.

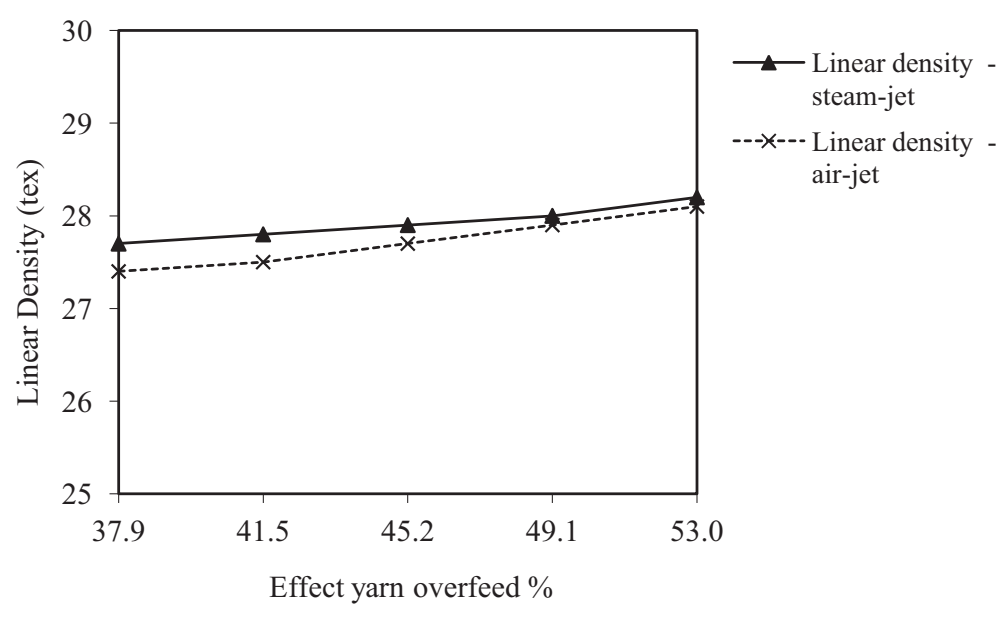

Figure 15 Effect of effect-yarn overfeed on linear density of textured yarns. 


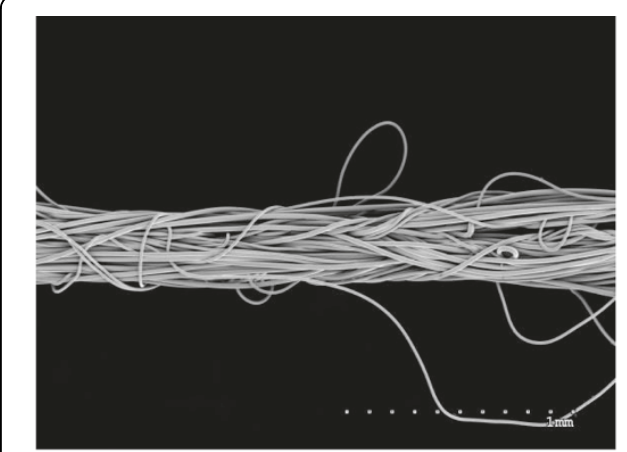

Steam-jet : overfeed at $37.9 \%$

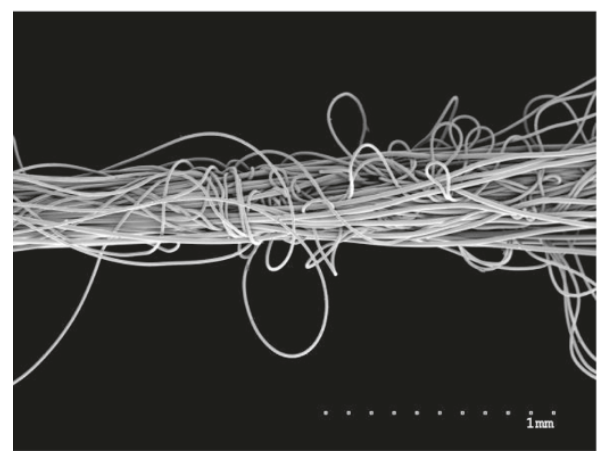

Steam-jet : overfeed at $53.0 \%$

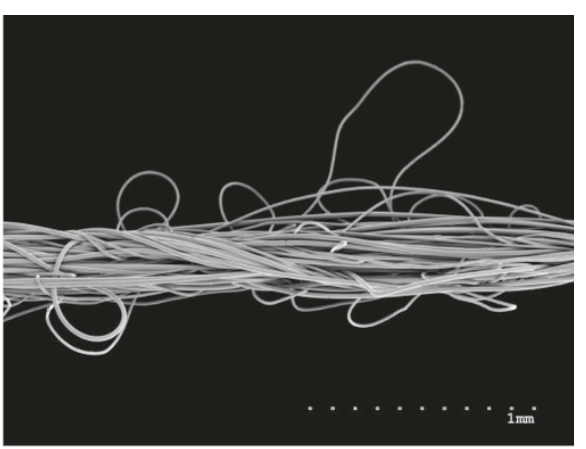

Air-jet : overfeed at $37.9 \%$

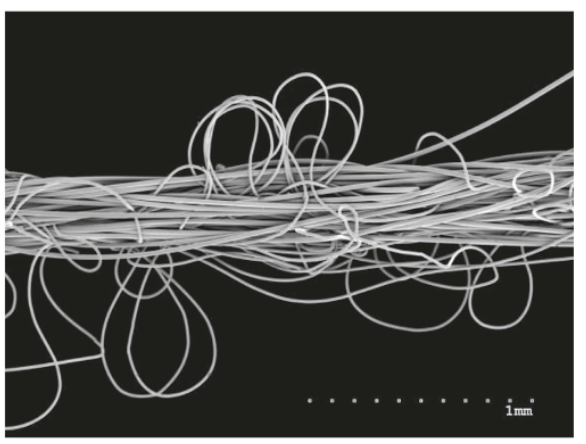

Air-jet : overfeed at $53.0 \%$

Figure 16 SEM images of typical steam-jet and air-jet textured yarns at $37.9 \%$ and $53.0 \%$ overfeeds.

\section{Sewing thread trials}

Both air-jet and steam-jet textured yarns were twisted, finished, lubricated and converted to sewing threads using industrial facilities. Commercial air-jet textured thread specifications for twisting, finishing, and lubrication were applied to all the samples. The yarns were twisted to a twist level of 400 turns per meter and made into single ply, Z twisted sewing threads.

Sewability tests were carried out according to the below specifications.

Sewing speed: 5,500 stitches per minute.

Needle size: 70 metric (for 250dtex threads)

Stitch density: 5 stitches per $\mathrm{cm}$

Stitch type: FS 301 lock stitch

Fabric type: Cotton / two plies

Weight of Fabric: $115 \pm 10 \mathrm{~g} / \mathrm{m}^{2}$

As per the results shown in Table 1, it can be concluded that effect yarn overfeeds up to 41.5 percent is suitable for 120 TKT spun-like textured sewing threads. Loop density of both the air-jet and the steam-jet textured yarns were increased when the effect-yarn overfeed was increased. Higher loop density will increase the surface friction as well as unevenness of the sewing thread surface. Further, standard effect-yarn overfeed for 120 TKT air-jet textured sewing thread is 37.9 percent. Therefore, sewability results confirm that the steam-jet textured 
Table 1 Sewability results

\begin{tabular}{lll}
\hline Effect-yarn overfeed \% & Sewability (thread breaks/250 $\mathbf{~})$ & \\
\cline { 2 - 3 } & Steam jet & Air-jet \\
\hline 37.9 & 0 & 0 \\
41.5 & 0 & 0 \\
45.2 & 3 & 4 \\
49.1 & 7 & 6 \\
53.0 & Not tested & Not tested \\
\hline
\end{tabular}

yarn is capable of manufacturing sewing threads at similar draw and overfeeds as air-jet textured yarns.

\section{Conclusion}

Increasing effect-yarn draw and effect-yarn overfeed increases the level of texturing and reduces strength, elongation and tenacity in both steam-jet and air-jet textured yarn. When the steam-jet textured yarn is considered, it can be concluded that spun-like textured yarn can be made satisfactorily using steam as an alternative fluid to air. Steam-jet textured yarn has a similar filament entanglement structure to air-jet textured yarn. Steam-jet textured yarn has a stronger and more compact structure than air-jet textured yarn where the steam-jet yarn loops are shrunken due the effect of heat setting. Furthermore, steam-jet textured yarn has less shrinkage and therefore post intermingled heat setting could be eliminated and the production cost of the spun-like textured yarn using steam could further be reduced. Increasing effect-yarn overfeed increases the loop density of textured yarns and therefore have more protruding loops in the textured yarn structure. However, higher effect-yarn overfeed increase the effect-yarn consumption and increase the linear density of the textured yarn. This would increase the production cost per unit length of yarn.

However, the loop density results and the microscopic inspections show that the textured yarn produced by higher effect-yarn overfeeds have bigger and more frequent loops. As found by Koc et al. (2008) this may be an advantage due to higher adhesion properties in the case of technical and industrial textile applications where fibre based composites such as tires, conveyer belts, hoses etc. are made.

When the sewability results of the sewing threads are concerned, it can be concluded that steam-jet textured sewing thread is as good as air-jet sewing thread. Furthermore, effect-yarn overfeed of approximately $37.9 \%$ which is the standard level of overfeed used by commercial 120TKT air-jet textured sewing threads. It seems the same effect-yarn overfeed level is suitable for steam-jet textured 120TKT sewing threads as well.

In general, steam generation cost is comparatively lower than compressed air generation cost. If the identical jets are used, steam consumption is less than air consumption in terms of $\mathrm{Kg} /$ hour. Therefore, when the steam-jet and air-jet textured yarns are compared, it can be concluded that steam-jet textured yarn 
is more economical to produce than air-jet textured yarn. Furthermore, environmental friendly alternative fluids such as biomass could be used to produce steam.

\section{Competing interests}

The authors declare that they have no competing interests.

\section{Authors' contribution}

GLDW and PWF conceived and designed the experiments. GLD Wickramasinghe performed the experiments, analyzed the data and wrote the manuscript. Both authors read and approved the final manuscript.

\section{Author details}

'Department of Textile and Clothing Technology, University of Moratuwa, Moratuwa 10400,

Sri Lanka. ${ }^{2}$ University of Manchester, Manchester, UK.

Received: 21 February 2014 Accepted: 15 April 2014

Published online: 02 July 2014

\section{References}

Acar, M. (1988). Factors governing the choice of supply yarns suitable for air-jet texturing. Man-made Fibre Yearbook (CTI), 1988, 90-95.

Acar, M. (1991). Trends in air-jet texturing. Man-made Fibre Yearbook (CTI), 1991, 94-96.

Acar, M, \& Demir, A. (1987). Air-jet texturing present and future, international conference. University of: Loughborough, UK. Explanation of how and why yarn wetting improves the air-jet texturing process.

Acar, M, \& Wray, GR. (1986). An analysis of the air-jet yarn texturing process. A brief history of development in the process, Journal of the Textile Institute, $77(1), 28-43$.

Acar, M, Turton, RK, \& Wray, GR. (1986a). An analysis of the air-jet yarn texturing process, part II: an experimental investigation of the air-flow. Journal of the Textile Institute, 77(1), 28-43.

Acar, M, Turton, RK, \& Wray, GR. (1986b). An analysis of the air-jet yarn texturing process, part III, filament behaviour during texturing. Journal of the Textile Institute, 77(4), 235-246.

Acar, M, Turton, RK, \& Wray, GR. (1986c). An analysis of the air-jet yarn texturing process, part IV: fluid forces acting on the filaments and the effect of filament cross sectional area and shape. Journal of the Textile Institute, $77(4), 247-254$

Acar, M, Turton, RK, \& Wray, GR. (1986d). An analysis of the air-jet yarn texturing process, part V, the effect of wetting the yarns. Journal of the Textile Institute, 77(6), 359-370.

Acar, M, Turton, RK, \& Wray, GR. (1986e). An analysis of the air-jet yarn texturing process. Part VI, the mechanism of loop formation, Journal of the Textile Institute, 77(6), 371-376.

Acar, M, Bilgin, S, Versteeg, HK, Dani, N, \& Oxenham, W. (2006). The mechanism of the air-jet texturing: the role of wetting, spin finish and friction in forming and fixing loops. Textile Research Journal, 76(2), 116-125.

Bilgin, S, Versteeg, HK, \& Acar, M. (1996). Effect of nozzle geometry on air-jet texturing performance. Textile Research Journal, 66(2), 83-90.

Demir, A, Acar, M, \& Turton, RK. (1987). A basic understanding of the air-flow in texturing nozzles (pp. 59-66). Present and Future, Loughborough, UK: International Conference on Air-jet Texturing.

Demir, A, Acar, M, \& Wray, GR. (1988). Air-jet textured yarns: the effect of process and supply yarn parameters on the properties of textured yarns. Textile Research Journal, 58(6), 318-328.

Fisher, KE, \& Wilson, DK. (1982). Proceedings of the $66^{\text {th }}$ textile institute annual conference. Lucerne: Switzerland. Air-jet texturing - an alternative to spun yarn production.

Koc, SK, Hockenberger, AS, \& Wei, Q. (2008). Effect of air-jet texturing on adhesion behaviour of polyester yarns to rubber. Applied Surface Science, 254, 7049-7055. doi:10.1016/j.apsusc.2008.05.310.

Kothari, VK, \& Timble, NB. (1991). Air-jet texturing: effect of jet type and some process parameters on properties of air-jet textured yarns. Indian journal of fibre \& textile research, 16, 29-38.

Kothari, VK, Sengupta, AK, \& Sensarama, JK. (1995). Effecct of baffle geometry and baffle setting on nep frequency, bulk and instability of air-jet textured yarns. Chemical fibers International (CFI), 45(April 1995), 140-142.

Kothari, VK, Chattopadhyay, R, \& Agrawal, P. (1996). Studies on filament migration in air-jet textured yarns and relationship between migration parameters and properties. Journal of the textile institute, 87(2), 335-348.

Mahmood, AH, Gong, RH, \& Porat, I. (2013a). Development of air-textured core-and-effect glass yarns for improving the bonding strength of laminated composites. Fibres and Polymers, 14(2), 271-276.

Mahmood, AH, Gong, RH, \& Porat, I. (2013b). Improvement in the fracture toughness (mode1) of glass fabric composites through air-jet texturing. Fibres and Polymers, 14(4), 591-596.

Rangasamy, RS, Kothari, VK, \& Sengupta, AK. (1990). Effect of specific characteristic on structural and properties of air-jet textured yarns, part 1: effect of filament fineness. Melliand Textilber, 71(9), E 301-302. 655-659.

Sengupta, AK, Kothari, VK, \& Alagirusamy, R. (1989). Influence of drawing variables on the properties of air-jet textured yarns made from POY polyester feeder yarns. Man-made Fibre Year book (CTI), 1989, 80-83.

Simmen, C. (1987). New developments in air-jet texturing of fine filament yarns. Chemiefasern/Textilindustrie, 37/89(10), 989-993. E126-E128.

Sivakumar, VR. (1975). The mechanism of bulking of air-textured yarns" Ph.D. Manchester: Thesis, university of Manchester. Versteeg, HK, Bilgin, S, \& Acar, M. (1994). Effects of geometry on the flow characteristics and texturing performance of air-jet texturing nozzles. Textile Research Journal, 64(4), 240-246. 
Wickramasinghe, GLD. (2003). Steam-jet intermingled sewing threads. University of Manchester, U.K.: Unpublished doctoral dissertation.

Wray, GR, \& Entwistle, JH. (1968). An investigation of the air-jet bulking process. Journal of the Textile Institute, $59,122-136$.

Wray, GR, \& Entwistle, JH. (1969). The modification of a taslan jet to operate at low air-pressure. Journal of the Textile Institute, 60, 411-419.

doi:10.1186/s40691-014-0005-6

Cite this article as: Wickramasinghe and Foster: Investigation of the influence of effect-yarn draw and effect-yarn overfeed on texturing performance: comparison between air-jet and steam-jet textured yarn. Fashion and Textiles 2014 1:5.

Submit your manuscript to a SpringerOpen ${ }^{\circ}$ journal and benefit from:

- Convenient online submission

- Rigorous peer review

- Immediate publication on acceptance

- Open access: articles freely available online

- High visibility within the field

- Retaining the copyright to your article

Submit your next manuscript at $>$ springeropen.com 